\title{
LAZER E USO PÚBLICO NO ENTORNO E NA RESERVA BIOLÓGICA DO TINGUÁ/RJ
}

\author{
Marcia Conceição Ferreira ${ }^{1}$ \\ Eduardo Ferreira ${ }^{2}$ \\ Emanuel Braga ${ }^{3}$ \\ Monika Richter ${ }^{4}$ \\ Silvia Souza ${ }^{5}$
}

\section{RESUMO}

A escassez de opções de lazer na Baixada Fluminense, localizada aproximadamente a $40 \mathrm{~km}$ das praias das Zonas Sul e Oeste do Rio de Janeiro, além de ser uma viagem onerosa e longa, leva a uma crescente procura por opções de lazer mais próximos da região. No período de férias escolares, a cada verão e, especialmente nos dias ensolarados e quentes como os registrados nos últimos anos, os balneários encontrados no entorno contíguo à Reserva Biológica do Tinguá - REBIO Tinguá - tem atraído um número cada vez maior de visitantes. Consequentemente, tem se observado maiores impactos ambientais provenientes deste uso público nas áreas próximas e até mesmo no interior da REBIO, embora seja categoria de Unidade de Conservação (UC) que não permite uso voltado para fins recreacionais. Dentre os impactos, destacam-se o aumento significativo de resíduos sólidos, oriundos do consumo de alimentos e bebidas, geralmente encontrados às margens dos rios, pichações em rochas, resquícios de lixo queimado e condições impróprias de balneabilidade em alguns locais em decorrência do excesso de pessoas. Dentro deste contexto, objetivou-se avaliar o perfil deste uso público, as motivações e características da visitação e a percepção ambiental dos frequentadores em relação à REBIO. Os resultados apontam que mais de $90 \%$ são provenientes da própria Baixada, tem como motivação as atividades de lazer relacionadas principalmente a banhos nas cachoeiras, tem consciência da problemática do lixo, embora sejam os responsáveis por este impacto e não vêem as comunidades de Jaceruba, Rio D'Ouro e outras áreas no interior da REBIO, como Tinguá e Xerém em Duque de Caxias, como localidades que integram a mesma Reserva.

Palavras-chave: Reserva Biológica do Tinguá, Lazer, Uso Público, Impacto Ambiental.

\author{
ABSTRACT \\ The scarcity of leisure facilities in the Baixada Fluminense, located approximately $40 \mathrm{~km}$ \\ from the beaches of the South and West Zones of Rio de Janeiro, besides being a costly and \\ long journey, leads to a growing demand for leisure facilities nearest the region. In the school \\ holidays, every summer and especially on sunny days and high temperatures as recorded in

\footnotetext{
${ }^{1}$ Graduanda de Turismo, Bacharelado UFRRJ/IM e Pesquisadora de Iniciação Cientifica pelo CNPQ. E-mail: marciaferreiratur@gmail.com

${ }^{2}$ Graduando de Turismo, Bacharelado UFRRJ/IM e Pesquisador de Iniciação Cientifica pelo CNPQ. E-mail: edubrazil@gmail.com

${ }^{3}$ Graduando de Turismo, Bacharelado UFRRJ/IM. E-mail: emanuelbragatur@ gmail.com

${ }^{4}$ Prof. Dra. De Geografia do Departamento de Educação e Sociedade UFRRJ/IM. E-mail: mrichter84@hotmail.com

${ }^{5}$ Mestranda em Geografia pela UERJ. E-mail: bjsilvia@ hotmail.com.br
} 
recent years, the spas found in the vicinity adjacent to the Biological Reserve Tinguá - REBIO Tinguá - has attracted an increasing number of visitors. And, consequently, there is greater environmental impact from this public use in the nearby areas and even inside the REBIO, although category of Conservation Unit (UC) that does not allow back use for recreational purposes. Among the impacts, it highlights the significant increase in solid waste, arising from the consumption of food and beverages, usually found on the banks of rivers, graffiti on rocks, burned garbage remnants, and improper conditions of bathing in some places due to excess of people. Within this context, the objective was to evaluate the profile of this public use, the visitation motivations and characteristics and the environmental awareness of the visitors regarding the REBIO. The results show that over $90 \%$ are from the Baixada Fluminense, is motivated leisure activities primarily related to bathing in waterfalls has garbage problem of consciousness, although those responsible for this impact and do not see the Jaceruba communities, Rio D'Ouro and other areas inside the REBIO as Tinguá and Xerem in Duque de Caxias, as members of the same protected area.

Keywords: Biological Reserve of Tingua, Leisure, Public Use, Environmental Impact.

\section{INTRODUÇÃO}

A Reserva Biológica do Tinguá, criada pelo Decreto nº 97.780 de 23 de maio de 1989, localiza-se no Estado do Rio de Janeiro e abrange quatro municípios: Nova Iguaçu, Duque de Caxias, Petrópolis e Miguel Pereira. Sua Zona de Amortecimento (ZA) definida no Plano de Manejo de 2006, abrange, além dos municípios já citados, Japeri e Queimados. Ainda segundo dados do Plano de Manejo, a Rebio-Tinguá ocupa uma área de 26.260 hectares, sendo sua maior porção, cerca de $55 \%$ e a sede da Unidade, situadas no município de Nova Iguaçu. A vegetação é do tipo Mata Atlântica com feições de Floresta Ombrófila Densa Submontona, Floresta Ombrófila Densa Montana e Floresta Ombrófila Densa Altomontana.

A Rebio-Tinguá representa $6 \%$ do total de área protegida do estado, sendo uma das mais importantes dentro do bioma de Mata Atlântica. A Unidade pertence à categoria de proteção integral, a mais restritiva em termos de uso. Tem por objetivo principal, a preservação do relevante fragmento de Floresta Atlântica e seu uso só pode ocorrer para fins educacionais e de pesquisa mediante autorização prévia (Lei Federal 9.985/00, Art. 10). Além disso, em março de 1991, a Rebio-Tinguá foi reconhecida pela UNESCO como Reserva da Biosfera.

De acordo com o Sistema Nacional de Unidades de Conservação/SNUC (Lei 9.985/00, Art.41), a Reserva da Biosfera é um modelo adotado internacionalmente, de gestão integrada, participativa e sustentável dos recursos naturais, com os objetivos básicos de preservação da diversidade biológica, desenvolvimento de atividades de pesquisa, monitoramento ambiental, educação ambiental, desenvolvimento sustentável e melhoria da qualidade de vida das populações.

Mesmo sendo relativamente recente, a Reserva Biológica do Tinguá já era protegida na época do império, por ordem do então Imperador D. Pedro II. Esta proteção se deve a importância da floresta enquanto produtora de água. Posteriormente, com o Código Florestal de 1934, o governo federal criou as Florestas Protetoras da União de Tinguá, Xerém e 
Mantiqueira, tornando-as terras de domínio público federal de natureza inalienável (MARTINS, 2011).

Atualmente, embora de proteção integral e cujo uso público somente para fins educacionais, em decorrência da falta de áreas de lazer dentro ou próxima à Baixada Fluminense, faz com que os moradores da região procurem a área da Reserva como opção de lazer. Outras, como as praias da zona sul e oeste do município do Rio de Janeiro ficam distantes e onerosas para a maioria da população desta região, ou seja, a Rebio-Tinguá vem sendo há anos a forma de lazer de parte desses moradores.

Para Dumazedier, (1976, apud MACEDO, OLIVEIRA, 2010, p. 44), o lazer é importante para o desenvolvimento pessoal e social do individuo, após cumpridas as suas obrigações profissionais, familiares e sociais. Segundo Requixa, (1977 apud MACEDO, OLIVEIRA, 2010, p. 44), o lazer é o conjunto de ocupações não obrigatórias, de livre escolha do individuo que vive e cujos valores propiciam condições de desenvolvimento pessoal e social. Ou seja, segundo os autores, para que o individuo se desenvolva pessoalmente e socialmente, ele precisaria de horas de lazer durante e após uma semana de trabalho e obrigações. $\mathrm{O}$ individuo sente a necessidade do lazer, a procura pelas águas cristalinas do Tinguá e o preço mais acessível passa a ser uma opção de lazer para a sociedade de baixa renda.

Diante do exposto, o presente trabalho, teve o intuito de identificar o perfil dos visitantes dessas localidades no entorno da REBIO Tinguá, bem como algumas dentro da propria UC, buscar compreender suas motivações, os impactos causados pelo uso e analisar como percebem a relação com este espaço protegido.

\section{MATERIAIS E MÉTODOS}

Para a elaboração do presente artigo foram consultadas diversas fontes bibliográficas entre artigos, teses, dissertações, capítulos de material didáticos da Fundação CECIERJ e de livros. A pesquisa baseou-se no estudo dos conceitos de UCs, lazer, uso público em UCs e conflitos de uso público.

$\mathrm{Na}$ segunda etapa foram realizados trabalhos de campo no período enttre janeiro e maio deste ano, sendo o primeiro para reconhecimento e observação participante e os outros três para aplicação de questionários e entrevistas. Apos, foram realizados o processamento e a analise dos dados levantados. Foram aplicados 24 questionários, buscando identificar diferentes eixos temáticos: conhecimento a respeito da REBIO do Tinguá, sobre a dinâmica do uso da Reserva, sobre a percepção ambiental da mesma e por fim o perfil dos entrevistados.

\section{RESULTADOS E DISCUSSÕES}

A partir das visitas a campo e entrevistas com a população que se encontrava no local, percebeu-se que a Reserva, vem há anos sendo a opção mais viável de lazer para um número considerável de pessoas, tanto dos municípios da Baixada como do Rio de Janeiro. Um dos 
entrevistados mora no bairro de Campo Grande e foi até a Unidade em "busca de momentos de paz e reflexão", alegando que "o contato com a natureza e com a beleza do local o leva a refletir e a melhorar como pessoa". Assim como esse morador, outros buscam o mesmo objetivo. Essa fala reforça a ideia de Dumazedier, 1967 e Requixa, 1977 (apud MACEDO, OLIVEIRA, 2010, p. 44), quando diz que o lazer é importante para o desenvolvimento pessoal e social do indivíduo. Já outros indivíduos vão simplesmente se banhar nas águas dos rios da reserva enquanto o churrasco que é feito ali mesmo está sendo preparado

Até o presente momento foram feitas 04 visitas à região da Rebio-Tinguá, com intervalos entre 30 a 40 dias. A cada visita foi possível observar um aumento da degradação nas áreas analisadas. Na primeira visita foi encontrado lixo e fezes humanas na UC. Já na segunda visita observou-se um aumento do lixo e algumas pichações. A quantidade de lixo vem aumentado visivelmente nessa parte da Unidade, localidades de Jaceruba e Rio D'Ouro/Nova Iguaçu, surpreendendo de forma negativa as análises durante a terceira visita.

O que mais ressaltou na quarta visita foi o aumento de pichações, todas as rochas do Poço do Sabonete estavam pichadas. O aumento de lixo e pichações ocorreu num pequeno espaço de tempo, já que a primeira visita foi em janeiro e a quarta no final de abril.

A partir das análises de campo, observou-se que no verão o fluxo de visitantes em Jaceruba é maior na parte externa da reserva, onde os próprios moradores represam a água formando piscinas naturais. Segundo funcionários da CEDAE e a funcionária de uma pousada, o fluxo dentro da reserva, na parte do Cachoeirão (nome dado pelos funcionários), é de 1000 pessoas por dia. No entanto, a Reserva é de uso restrito, não permitindo nenhum tipo de interferência humana no se interior, mesmo que seja para apreciar a beleza cênica do lugar. Segundo alguns entrevistados, o aumento do uso em Jaceruba deve-se a modificações do leito do rio ocorridas apos as chuvas de 2011 em Rio D’Ouro e a intensificação de físcalização no bairro Tinguá, onde comumente eram encontradas barragens construidas pelos donos de estabelecimentos comerciais do entorno. Esses entrevistados ressaltam que Jaceruba é o único local com água boa e limpa, esse fato resulta na migração dos visitantes. Outro visitante, entrevistado no segundo campo, disse que frequenta a Reserva há mais de 15 anos, porém em sua adolescência e juventude ele frequentava o bairro Rio D'Ouro que segundo ele era “o paraíso". Ressalta ainda, que em verões passados, chegavam a parar 10 ônibus de excursão, esses desembarcavam seus passageiros que adentravam a Reserva por Rio D’Ouro. Esta conduta mostra que a fala dos frequentadores diverge das suas atitudes, já que a maioria (42\%) respondeu que a função da Reserva é a preservação da natureza (Figura 1), entretanto, a Unidade sofre com grandes pressões por parte da população no que se refere ao lazer. 


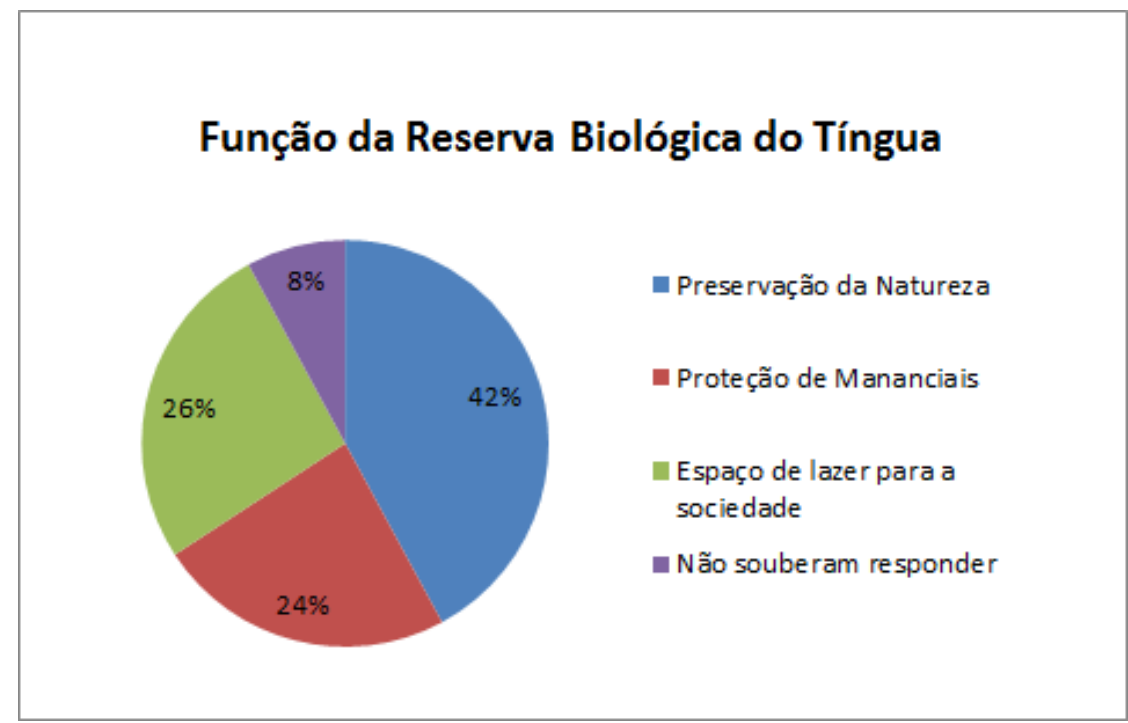

Figura 01. Qual a função da Reserva Biológica do Tinguá na percepção dos visitantes?

Em campo, é possível observar a divergência entre a fala dos entrevistados e suas atitudes. Observa-se no local o descaso dos mesmos com o próprio lugar escolhido ou de mais fácil acesso para o lazer em família, como se constatou em outro questionamenteo sobre como costuma visitar a REBIO Tinguá e seu entorno (Figura 02).

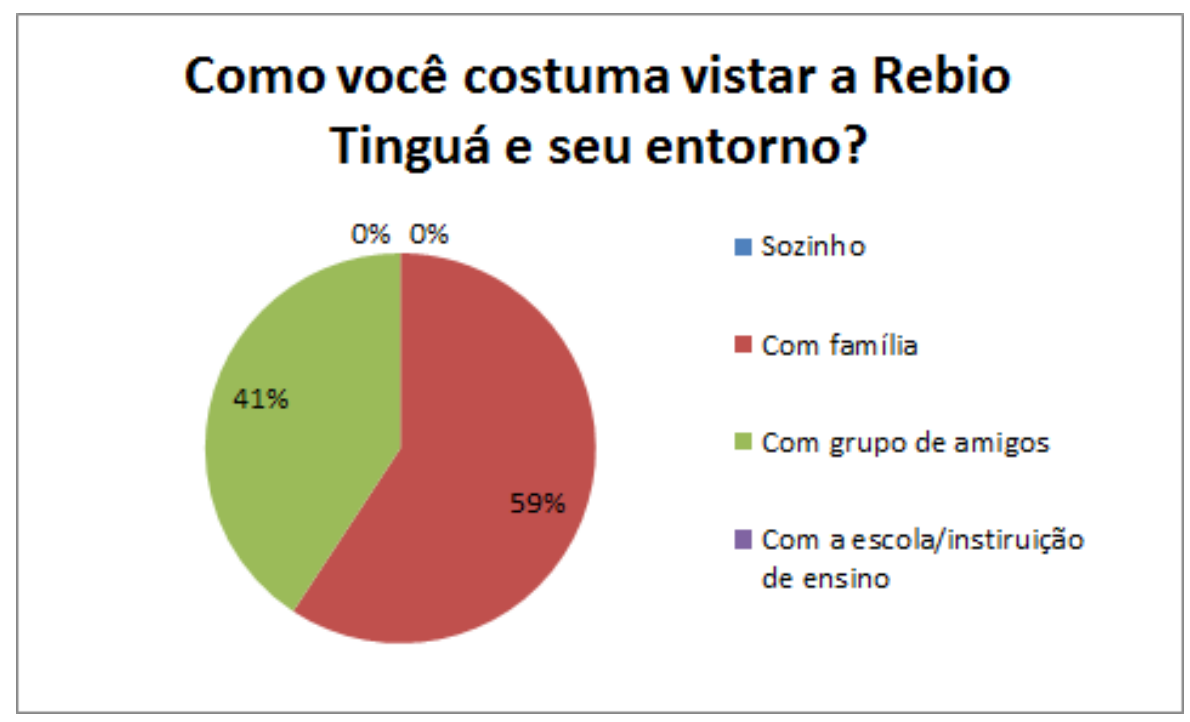

Figura 02. Como você costuma visitar a Rebio Tinguá e seu entorno?

Os resultados apontam que a maioria dos entrevistados reconhece a função principal da Reserva, mas a realidade em campo demonstra que os rios da Reserva estão sendo utilizados por um número excessivamente elevado de visitantes (Figura 03). 


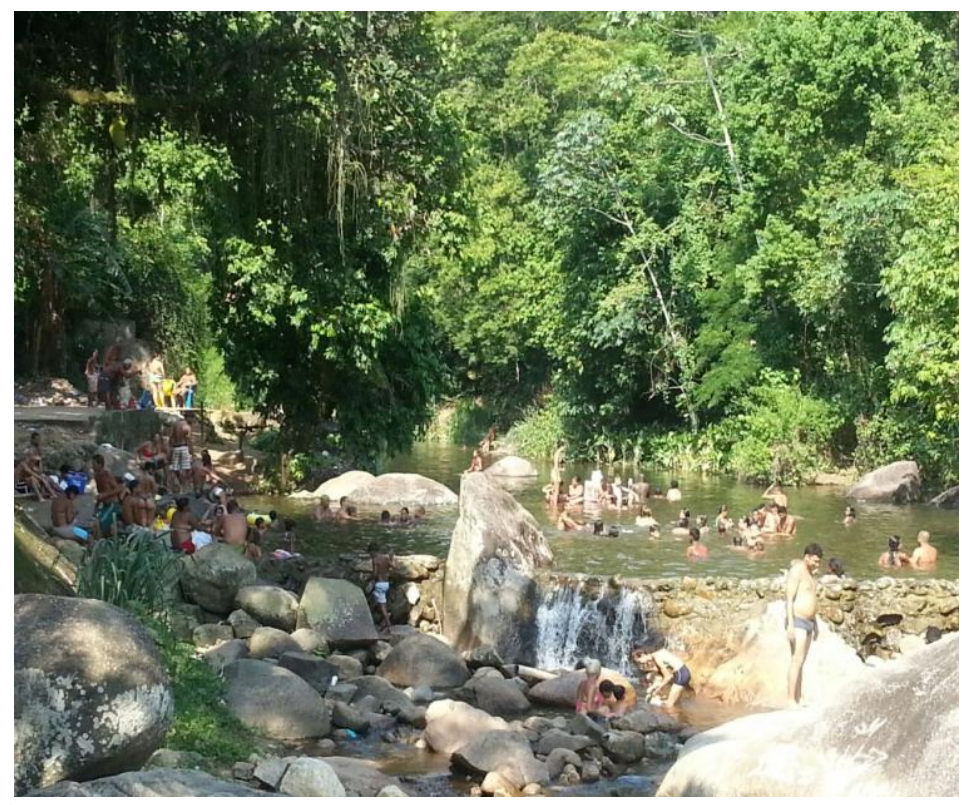

Figura 03. Área de preservação permanente em Jaceruba sendo utilizada de forma indiscriminada. Em primeiro plano observa-se barragem construída no leito do rio que faz divisa com a REBIO Tinguá. Fonte: Marcia Ferreira. Janeiro, 2015.

Quanto à motivação (Figura 04), 88\% dos entrevistados disseram usar o local para lazer, principalmente para banho e churrasco, sendo que essas atitudes vão de encontro tanto com a preservação da natureza, quanto ao que dispõe o SNUC refrente a categoria REBIO. Ressalta-se que um churrasco dentro de área florestada pode causar incêndio nesta. Acrescenta-se ainda, a enorme quantidade de lixo deixado pelos visitantes.

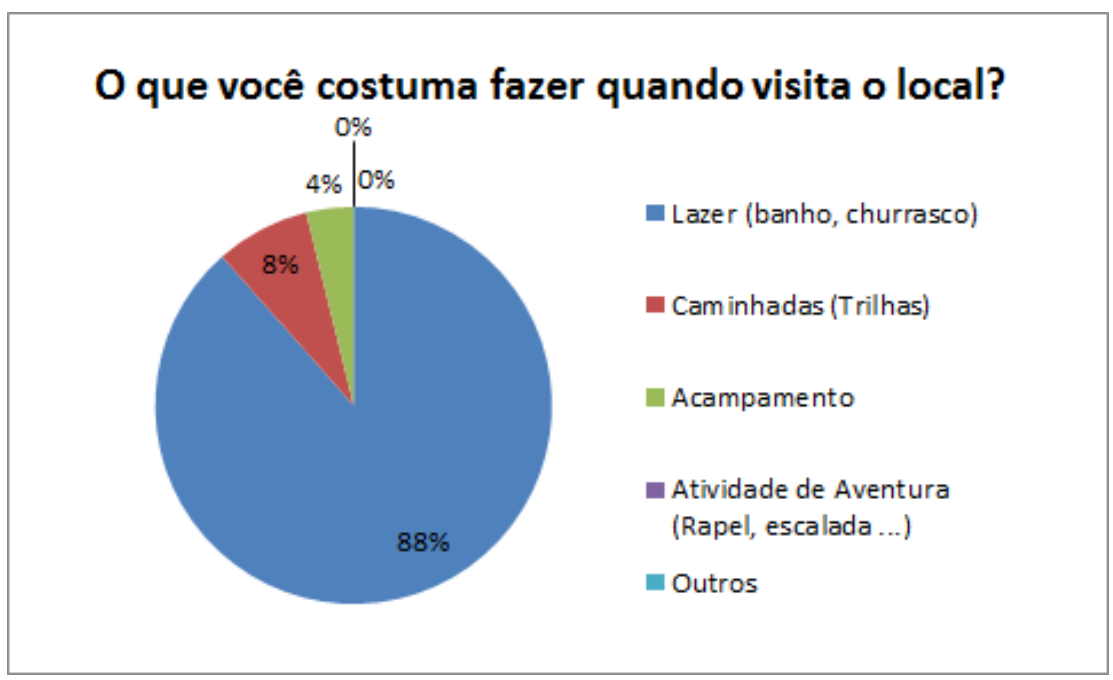

Figura 04. O que você costuma fazer quando visita o local?

Esse tipo de uso predatório e indiscriminado por conta dos usuários pode vir a causar grandes prejuízos ao ambiente, refletindo na vida dos moradores e inclusive no lazer dos banhistas, já que é visivel a degradção da qualidade da água em termos de turbidez nos horários de maior demanda. 
Segundo Leuzinger (2010), o uso desordenado de uma UC pode causar danos irreversíveis:

Os riscos, contudo, devem ser considerados e abarcam a destruição da vegetação, a erosão nas trilhas, o lixo deixado pelos visitantes, além de ameaças como danos que afetam a evolução dos ecossistemas, alteram o comportamento da fauna e/ou induzem a sua migração. (Leuzinger, 2010)

E de acordo com Takahashi (2004, apud LEUZINGER, 2010) o pisoteio nas trilhas em alto nível pode levar a extinção de espécies.

O pisoteio nas trilhas, mesmo quando produz baixo impacto, reduz a vegetação rasteira, a biomassa e pode alterar a composição da flora mediante a eliminação de espécies frágeis. Em altos níveis, pode acarretar alteração na composição ou mesmo perda completa da vegetação forrageira, extinção de espécies, compactação do solo, alargamento da trilha e diminuição da taxa de infiltração (TAKAHASHI, 2004, apud LEUZINGER, 2010).

Esses danos podem ocorrer até mesmo nas áreas monitoradas com previsão legal para uso publico de recreação, como os parques. A diferença entre o uso numa área monitorada e não monitorada está na forma em que este uso é previsto. Áreas mais sensíveis em um Parque, por exemplo, são protegidas. Numa Unidade de proteção integral, onde esse uso não pode ocorrer, este ocorre sem nenhum critério. Problema que pode levar a transformações no ambiente. A abertura de trilhas, por exemplo, vem ocorrendo em toda extensão da reserva, tanto em Jaceruba quanto na estrada que delimita a UC. Estas são abertas de forma desordenada, mesmo nos lugares que possuem cercas para delimitar a Unidade, ou seja, a Rebio Tinguá é invadida e degradada constantemente.

No quarto campo havia um fluxo maior de visitantes, algumas pessoas entravam e saiam na floresta pela cerca que se encontra danificada pelos banhistas. Esse caminho leva até o interior da Reserva. No entanto, o Art. 10 da Lei 9.98500 estabelece que: "A Reserva Biológica tem como objetivo a preservação integral da biota e demais atributos naturais existentes em seus limites, sem interferência humana direta ou modificações ambientais", ou seja, é proibida a entrada de pessoas para o lazer ou qualquer outra atividade que não seja para fins educacionais, mesmo assim, a entrada deve ser autorizada. Mas o que condiz com a lei não faz parte da realidade da Rebio do Tinguá. Fato constatado pelo trabalho de campo e aplicação dos questionários. Praticamente, todos os entrevistados vão à Reserva para o lazer, e, consequentemente, quando se deparam com espécies nativas da região se assustam, como um grupo de adolescentes que tentou matar uma cobra que estava no rio, dentro da Reserva. Vários grupos de visitantes agem da mesma forma. Entram onde é proibido e quando percebem a presença de animais que identificam como perigosos, se "defendem" de um possível dano, eliminando-o. Algumas espécies, inclusive, podem estar ameaçadas de extinção ou serem raras. 
Acrescenta-se que segundo um entrevistado, no bairro Rio D'Ouro ocorreu o mesmo problema. Eram montadas churrasqueiras com seixos dos rios dentro da UC. Esse mesmo entrevistado, disse que anteriormente "pescava-se até camarão". Afirmou vir gente de todas as partes do Rio, as pessoas entravam e permaneciam o dia todo na Reserva", ele afirma que "não tem mais peixe nesses rios, que está "acabado, tudo sujo e abandonado", e deseja que o mesmo não ocorra em Jaceruba.

\section{CONCLUSÕES E CONSIDERAÇÕES FINAIS}

A Rebio-Tinguá, além de dotada de notável relevância paisagística e ambiental, possui em seu interior incontáveis cachoeiras. Este fator intensifica o uso público, mesmo não sendo permitido. A partir das pesquisas de campo realizadas na região, ficou claro o uso predatório. A aplicação de questionários, assim como as entrevistas realizadas, contribuiram para identificar as atividades praticadas pelos visitantes, tais como poluição do local por meio de lixo e "oferendas" religiosas, pichação nas rochas, bem como a construção de barragens artificiais e realização de fogueiras com as pedras/seixos do rio, além da abertura indiscriminada de trilhas.

Além disso, ficou claro a falta de entendimento por parte dos entrevistados sobre o que é uma Unidade de Conservação, suas categorias, o que é permitido ou não. São poucos os que sabem que ali é uma Reserva, e mesmo os que sabem, não compreendem o que é uma Reserva Biológica, quais são as suas restrições de uso e os objetivos de criação. Alguns visitantes dizem saber que estão proximos a Rebio, mas não possuem noção de seus limites. Quando questionados se estavam dentro da Reserva, diziam não saber. Para a maioria, a função da Rebio Tinguá é a preservação da natureza e a proteção de mananciais de água, no entanto, não deixam de mencionar o lazer da população, sendo esta a principal motivação de suas visitas.

No último trabalho de campo realizado, notou-se que o volume de água do Poço do Sabonete (nome informado pelos funcionários da CEDAE) estava bem abaixo do normal. Este se localiza após a captação de água realizada pela empresa, sendo um dos conflitos de gestão da Unidade. Também foi verificado que o número de pichações aumentou significativamente. O lixo, sem dúvida, é um dos maiores problemas da região, já que, quando não é deixado às margens do rio, é queimado dentro das churrasqueiras improvisadas, gerando mau cheiro e fumaça tóxica em decorrência das embalagens plásticas. Acrescenta-se que a queima é perigosa em área da floresta, podendo causar incêndios no seu entorno ou interior, além de provocar danos à saúde dos moradores.

A fala de alguns visitantes mais antigos deixa claro que se nada for feito, o bairro de Jaceruba vai degradar de forma rápida e talvez irreversível, a exemplo do que se observa em Rio D'Ouro. Por outro lado, não se pode esquecer as demandas da sociedade, essas pessoas precisam de áreas de lazer. O entorno da Rebio poderia ser aproveitado para o lazer da população, que o mesmo fosse feito de forma consciente, dentro de um planejamento adequado ao entorno da Unidade. Tanto a gestão municipal quanto a gestão da UC, precisam trabalhar juntas e pensar em meios de conciliar a proteção da natureza com o bem estar da sociedade num todo, um não pode excluir o outro. 
No geral, a percepção dos entrevistados a respeito da Rebio Tinguá é positiva, já que todos relacionam a área ao bem estar em decorrência da qualidade da água, do ar, da beleza paisagística e da temperatura amena em dias de calor intenso. A maioria diz que aquele lugar é muito importante pra eles, especialmente pela condição de lazer que proporciona. Dizem que a natureza precisa ser preservada, alguns até falavam que é preciso preservar a floresta para que a água não acabe. Entretanto, não percebem que o uso na forma como é feito, depreda e degrada o local. Ou seja, a fala dos entrevistados é contraditória em alguns momentos, indicando que há de fato a necessidade de melhor trabalhar aspectos de uma educação ambiental crítica, buscando demonstrar que o uso consciente dos recursos hídricos para lazer, no lado externo à REBIO Tinguá, pode ser tão agradavel quanto no interior da mesma, basta minimizar os impactos que são causados, que pode se dar pelo ordenamento da ativiadade de lazer nestas localidades, contando com a presença do poder público, principalmente do municipal, já que boa parte do entorna da Reserva é constituído por UCs municipais, de gestão da Prefeitura de Nova Iguaçu, na categoria APA.

\section{AGRADECIMENTOS}

Ao CNPq pelas bolsas de iniciação científica (PIBIC) concedidas; ao Flávio Silva, chefe da REBIO, pelo apoio na realização da pesquisa e as comunidades residentes no entorno da REBIO em especial a de Jaceruba.

\section{BIBLIOGRAFIA CONSULTADA}

ARRUDA, R. "Populações tradicionais" e a proteção dos recursos naturais em unidades de conservação. Ambiente e Sociedade - Ano II. n. 5, 2º semestre, 1999.

BRITO, D. M. C. Conflitos em unidades de conservação. Revista de Humanidades do Curso de Ciências Sociais UNIFAP. n,1, Dez 2008. Disponível em: <http://periodicos.unifap.br/index.php/pracs/article/view/10/n1Daguinete.pdf> Acesso em $20 / 02 / 15$

FREIRE, E. S.; LEMOS, L. O. Uso público no parque nacional do Itatiaia. In: VII CONGRESSO BRASILEIRO DE GEÓGRAFOS, Agosto, 2014. Anais ... Vitória/ES: Associação dos geógrafos brasileiros.

GOMES, C. L. Verbete Lazer - Concepções. In: GOMES, CHRISTIANNE L. (Org.). Dicionário Crítico do Lazer. Belo Horizonte: Autêntica. Editora, 2004. p. 119-126.

GOMES, C. M. e DANTAS, S. Lazer. v. 1, Rio de Janeiro: Fundação. CECIERJ, Cons. Cederj, 2012.

LEUZINGER, M. D. Uso Público em Unidades de Conservação. In: Congresso de Direito Ambiental da PUC-RIO, Rio de Janeiro, 1. 19 p. 2010 
LOUREIRO, C. F. B. e CUNHA, C. C. Educação ambiental e gestão participativa de unidades de conservação: Elementos para se pensar a sustentabilidade democrática. Ambiente e Sociedade. Campinas, v. XI, n. 2, p. 237 - 253, jul./dez. 2008.

MACEDO, A. P. e OLIVEIRA, M. A. S. A. O conceito de lazer. Turismo e Sociedade, v. 2, mód. 2, 3 e 4, cap.12, p. Rio de Janeiro: Fund. CECIERJ, Cons. Cederj, 2010/1

MARTINS, A.L. Lazer e Áreas Protegidas: conflitos na busca de "emoções agradáveis" . Ambiente e Sociedade. Campinas, v. XIV, n. 2 p. 51 -67, jul.-dez. 2011

MEDEIROS, M. Turismo, unidade de conservação e conflito em Ilha Grande (Angra dos Reis, RJ): o caso da comunidade da Vila do Aventureiro. Caderno Virtual de Turismo. v. 10, n.3, 2010. Disponível em: http://www.ivt.coppe.ufrj.br/caderno/index.php?journal=caderno\&page=article\&op=view\&pa th\%5B\%5D=445\&path\%5B\%5D=255> Acesso: 05/03/15.

PlanAlTo. Presidência da República Casa Civil. Subchefia para Assuntos Jurídicos. Disponível em: $<$ http://www.planalto.gov.br/ccivil_03/leis/2002/110406.htm> Acesso em: $10 / 04 / 15$.

PONTES, J. A. L e MELLO, F. A. P. Uso público em unidades de conservação de proteção integral: considerações sobre impactos na biodiversidade. Anais ... Uso Público em Unidades de Conservação, n. 1, v. 1, 2013. Niterói - RJ.

PUKE, N. e MARCELLINO, NELSON. CARVALHO. Contribuições de alguns autores de três das principais escolas antropológicas para o estudo do lazer: Evolucionista, Culturalista e Funcionalista. Licere. Belo Horizonte, v. 15, n.3, set, 2012.

SOUZA, P. C. e MARTOS, H. L. Estudo do uso público e análise ambiental das trilhas em uma unidade de conservação de uso sustentável: Floresta nacional de Ipanema, Iperó - SP. Viçosa - MG, v.32, n.1, p. 91-100, 2008.

TUAN, YU-FU. Espaço e Lugar - A Perspectiva da Experiência - Tradução Lívia de Oliveira, Prof. Adjunta do Depto. de Geografia - UNESP - Rio Claro, SP. 1983, 250p.

VIVACQUA, M. e VIEIRA, P. F. Conflitos socioambientais em unidades de conservação. Política e Sociedade. n. 7, p. 139 -162, out. 2005. 